\title{
O MST e a formação dos sem terra: o movimento social como princípio educativo
}

ROSELI SALETE CALDART

"Quando ocupamos aquela terra, paramos de morrer ..."

(Domício, Sem Terra do Assentamento Ireno Alves, MST, antiga Fazenda Giacometti, Paraná, Brasil).

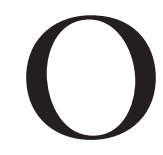

Movimento Dos Trabalhadores Rurais Sem Terra, também conhecido como Movimento dos Sem Terra ou MST, é fruto de uma questão agrária que é estrutural e histórica no Brasil. Nasceu da articulação das lutas pela terra, que foram retomadas a partir do final da década de 70 , especialmente na região Centro-Sul do país e, aos poucos, expandiu-se pelo Brasil inteiro. O MST teve sua gestação no período de 1979 a 1984, e foi criado formalmente no Primeiro Encontro Nacional de Trabalhadores Sem Terra, que se realizou de 21 a 24 de janeiro de 1984, em Cascavel, no estado do Paraná. Hoje o MST está organizado em 22 estados, e segue com os mesmos objetivos definidos neste Encontro de 84 e ratificados no I Congresso Nacional realizado em Curitiba, em 1985, também no Paraná: lutar pela terra, pela Reforma Agrária e pela construção de uma sociedade mais justa, sem explorados nem exploradores (1).

Nos 16 anos completados na entrada dos anos 2000, o MST contabiliza um número de aproximadamente 250 mil famílias assentadas e de 70 mil famílias acampadas em todo o Brasil. Quantidades pequenas diante da realidade das mais de 4,5 milhões de famílias sem-terra existentes no país, mas significativas, dado o formato histórico da questão agrária entre nós, e a dignidade humana construída mediante tais números. O MST já registra em sua história áreas conquistadas do latifúndio que se tornaram lugares de vida e de trabalho para muitas famílias, e de produção de alimentos para mais outras tantas; hoje são 81 cooperativas de trabalhadores e trabalhadoras Sem Terra, 45 unidades agroindustriais e, o principal, a eliminação da fome e a redução drástica dos índices de mortalidade infantil nos assentamentos espalhados pelo Brasil inteiro.

O MST também registra em sua história, e com especial orgulho, as 100 mil crianças e adolescentes que estão estudando em escolas conquistadas em suas áreas de assentamento e acampamento, as cirandas infantis (2), que aos poucos vão 
produzindo a cultura da educação infantil no campo; um movimento massivo de alfabetização de jovens e adultos sem-terra, que envolve em torno de 20 mil educandos, e também a formação de técnicos e de educadores em cursos de nível médio e superior, assim como diversas outras iniciativas de formação de sua militância e do conjunto da família Sem Terra.

São conquistas de uma luta coletiva na qual muitas pessoas também perderam sua vida, seja no dia a dia da violência do latifúndio, seja em massacres mundialmente divulgados, como o caso de Eldorado dos Carajás, no Pará, em 1996. É assim que o MST vem ajudando a recolocar na agenda política brasileira a questão da Reforma Agrária: fazendo a luta pela terra e afirmando, em suas iniciativas, a possibilidade de novas relações sociais, e de um novo projeto de desenvolvimento para o campo, e para o país.

O MST tem chamado a atenção dos diversos segmentos da sociedade por apresentar determinadas características que o distinguem em sua trajetória de movimento social de trabalhadores e trabalhadoras do campo. Uma trajetória breve, diga-se, se o considerarmos dentro de um processo histórico mais amplo, mas longa se o compararmos com a maioria dos movimentos camponeses do Brasil, geralmente destruídos com muito menos tempo de vida. Destaco algumas destas características:

- A radicalidade do sen jeito de fazer a luta e os sujeitos que ela envolve. O MST reafirmou a ocupação do latifúndio como a principal forma de luta pela terra, e a mobilização em massa dos sem-terra como o jeito de fazê-la. Isto quer dizer que explicita nas próprias ações de luta o que contesta (enquanto prática e enquanto valor), e que sujeitos pretende trazer de volta à cena social em nosso país. A epígrafe que escolhi para este texto diz por si mesma do que aqui se trata. Quem olha para as ações do MST vê se transformarem em lutadores seres humanos que o capitalismo já imaginava ter excluído definitivamente. Talvez seja esta radicalidade, da luta, do jeito e de quem a faz, o que provoca na sociedade tomada de posição imediata: as pessoas são contra ou são a favor das ações do MST; mas de modo geral não costumam ficar indiferentes a elas.

- A multiplicidade de dimensões em que atua. O MST tem na luta pela terra seu eixo central e característico, mas as próprias escolhas que fez historicamente sobre o jeito de conduzir sua luta específica (uma delas a de que a luta seria feita por famílias inteiras), acabaram levando o Movimento a desenvolver uma série de outras lutas sociais combinadas. Estas lutas, bem como o trabalho cotidiano em torno do que são suas metas, e que envolvem questões relacionadas à produção, à educação, à saúde, à cultura, aos direitos humanos..., se ampliam à medida que se aprofunda o próprio processo de humanização de seus sujeitos, que se reconhecem cada vez mais como sujeitos de direitos, direitos de uma humanidade plena. 
- A combinação de formatos organizativos diversos. Exatamente para dar conta dos seus objetivos e das diversas dimensões de sua luta, o MST acabou construindo um tipo de organização que mistura a versatilidade de um movimento social, no qual entra todo mundo o tempo todo, com um xadrez de relações sociais e organizacionais próprias quase de uma instituição social, que se pretende flexível mas duradoura. Daí a lógica de uma verdadeira empresa social, convivendo com a irreverência de um movimento permanente e imprevisível. Os estudiosos de movimentos sociais de modo geral têm dificuldade de enquadrar o MST em suas classificações mais tradicionais. O MST tem resolvido este problema criando uma denominação para si próprio: uma organização social de massas, em que a combinação de características contraditórias se coloca exatamente como um dos pilares de sua identidade.

- A capacidade que vem construindo de universalizar, ou de tornar a sociedade como um todo, uma bandeira de luta que nasce de um grupo social específico e de seus interesses sociais imediatos. O lema Reforma Agrária uma luta de todos, trabalhado pelo MST especialmente a partir do seu III Congresso Nacional em 1995, sintetiza um passo muito importante na própria definição da identidade Sem Terra (3), que ao buscar educar a sociedade para que reconheça a Reforma Agrária como uma luta não apenas dos trabalhadores e das trabalhadoras da terra, também se educa para assumir bandeiras de luta cada vez mais amplas. O processo de construção desta característica tem levado a uma identificação cada vez maior das maiorias excluídas, bem como de outros sujeitos que com elas se identificam politicamente, com os Sem Terra e com o MST (4).

Neste Seminário foi proposta para nosso debate a relação entre exclusão social, trabalho, lutas sociais e educação na América Latina. Um dos desafios que nos coloca é exatamente o de repensar as práticas educativas e as matrizes pedagógicas de uma educação que se assuma como parte dos dilemas sociais deste final de século. Penso que uma das maneiras de fazer esta reflexão é olhar com mais atenção para os novos sujeitos sociais deste momento histórico, que vêm sendo produzidos pela dinâmica das lutas sociais que não aceitaram a exclusão como um dado inevitável. Ao buscarem reconquistar o direito ao trabalho e à dignidade, estes sujeitos e suas lutas nos ensinam algo mais sobre processos de transformação social, e sobre práticas de educação a eles vinculadas. Os movimentos sociais têm sido espaços de organização destas lutas e de formação destes sujeitos.

A reflexão que gostaria de trazer para este Seminário, desde o MST, diz respeito à necessidade - política e pedagógica - de pensarmos o movimento social também como uma das matrizes pedagógicas fundamentais na reflexão de um projeto educativo que se contraponha aos processos de exclusão social, e que ajude a reconstruir a perspectiva histórica e a utopia coletiva de uma sociedade com justiça social e trabalho para todos. 
Existe um jeito de olhar para o MST e sua trajetória histórica que nos permite enxergá-lo desde as preocupações da educação e da pedagogia, e é este olhar que eu gostaria de desenvolver para contribuir com a reflexão deste Seminário. Trata-se de olhar para o MST como lugar da formação do sujeito social Sem Terra, e para a experiência humana de ser do MST, e participar da cons-

\section{... por ser movido por uma luta social centrada em questóes de vida e morte ...} trução da coletividade Sem Terra, como um processo de educação, que é também um modo de produção da formação humana, tanto mais significativo do ponto de vista social, político e pedagógico, por ser movido por uma luta social centrada em questões de vida e morte e de vida inteira, porque vinculadas às raízes de um processo de humanização mais profundo: terra, trabalho, memória, dignidade.

A formação dos Sem Terra nos remete a um processo de fazer-se humano na história que está produzindo e sendo produzido em um movimento de luta social, também constituído como parte de um movimento socio-cultural mais amplo; mesmo sem que os Sem Terra tenham plena consciência disso, tal movimento extrapola seus interesses corporativos e projeta novos contornos para a vida em sociedade.

Os sem-terra do MST estão sendo sujeitos de um movimento que acaba pondo em questão o modo de ser da sociedade capitalista atual e a cultura reproduzida e consolidada por ela. Fazem isto não porque professem idéias revolucionárias, nem porque este seja o conteúdo de cada uma de suas ações tomadas em si mesmas. Contestam a ordem social pelo conjunto (contraditório) do que fazem nas ocupações, nos acampamentos, nos assentamentos, nas marchas, na educação de suas crianças, jovens e adultos; pelo jeito de ser de sua coletividade, que projeta valores que não são os mesmos cultivados pelo formato da sociedade atual; fazem isto, sobretudo, pelo processo de humanização que representam, e pelos novos sujeitos que põem em cena na história do país.

Uma luta que permite a um ser humano parar de morrer, só pode nos trazer lições fundamentais de pedagogia, principalmente se acreditarmos que em tempos de desumanidade crescente, a educação somente tem sentido como uma prática radical de humanização, ou de formação humana em seu sentido mais inteiro e profundo.

Continuo este texto apresentando algumas idéias-força que constituem o raciocínio produzido por este olhar, e que coloco para nosso diálogo neste, e a partir deste, Seminário.

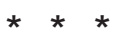




\section{Sem Terra é um nome próprio que identifica hoje um sujeito social e um processo de formação humana}

Para além das polêmicas existentes entre os estudiosos da questão agrária no Brasil, a respeito dos avanços e retrocessos da luta pela Reforma Agrária na conjuntura atual, e do papel político desempenhado pelo MST na reentrada deste tema na agenda do país, análise em que não pretendo entrar nos limites deste texto, há um fato social, histórico, e que é quase um consenso entre os analistas, sejam os movidos por preocupações conservadoras, sejam aqueles preocupados com o avanço das transformações sociais. O fato é que há no Brasil, hoje, um novo sujeito social que participa ativamente da luta de classes, com sua identidade e seu nome próprio: Sem Terra. Neste sentido, Sem Terra é mais do que semterra, exatamente porque é mais do que uma categoria social de trabalhadores que não têm terra; é um nome que revela uma identidade, uma herança trazida e que já pode ser deixada aos seus descendentes, e que tem a ver com uma memória histórica, e uma cultura de luta e de contestação social. Há um processo de construção deste sujeito, que é a história da formação do sem-terra brasileiro, em um recorte político e cultural diferenciado, algo que certamente requer estudos mais aprofundados.

Quando me refiro à formação dos Sem Terra trato - inspirada em Edward Thompson (5) - do processo pelo qual trabalhadores e trabalhadoras rurais semterra fizeram-se ou ainda fazem-se este novo sujeito social chamado Sem Terra, com uma identidade e uma consciência que os insere nos embates políticos do nosso tempo. Diz Thompson (1987: 9), ao explicar o sentido do fazer-se da classe operária inglesa, que se trata de compreendê-la como um processo ativo, que se deve tanto à ação humana quanto aos condicionamentos: "A classe operária não surgiu tal como o sol numa hora determinada. Ela estava presente ao seu próprio fazer-se" No caso de que aqui se trata, a paráfrase possível me parece ser: os sem-terra não surgiram como sujeitos prontos, ou como uma categoria sóciopolítica dada, mediante o ato de criação do MST. Sua gênese é anterior ao Movimento e sua constituição é um processo que continua se desenvolvendo ainda hoje, embora, tal como no caso da classe operária analisada por Thompson, já seja possível identificar um momento da sua história em que se mostra como identidade melhor definida. Este momento corresponde ao final da década de 80 e início dos anos 90, do final do século XX.

Ser Sem Terra é também mais do que lutar pela terra; Sem Terra é uma identidade historicamente construída, primeiro como afirmação de uma condição social: sem-terra, e aos poucos não mais como uma circunstância de vida a ser superada, mas como uma identidade de cultivo: Sem Terra do MST! Isto fica ainda mais explícito na construção histórica da categoria crianças Sem Terra, ou 
Sem Terrinha, que não distinguindo filhos e filhas de famílias acampadas ou assentadas, projeta não uma condição, mas um sujeito social, um nome próprio a ser herdado e honrado (6). Esta identidade fica mais forte à medida que se materializa em um modo de vida, ou seja, que se constitui como cultura, e que projeta transformações no jeito de ser da sociedade atual e nos valores (ou antivalores) que a sustentam.

Há duas dimensões fundamentais a serem compreendidas no processo de formação dos sem-terra ligados ao MST: a que vincula cada família Sem Terra à trajetória histórica do Movimento e da luta pela terra e pela Reforma Agrária no Brasil, tornando-a fruto e raiz (sujeito) desta história; a que faz de cada pessoa que integra o MST um ser humano em transformação permanente, à medida que sujeito (também condicionado a) de vivências coletivas que exigem ações, escolhas, tomadas de posição, superação de limites, e assim conformam seu jeito de ser, sua humanidade em movimento. Do entrelaçamento das vivências coletivas, que envolvem e se produzem desde cada família, cada grupo, cada pessoa, com o caráter histórico da luta social que representam, se forma então a coletividade Sem Terra, com uma identidade que não se enxerga olhando para cada pessoa, família ou grupo de sem-terra em si mesmos, mas que se sente ou se vive participando das ações ou do cotidiano do MST.

A trajetória histórica do MST pode ser interpretada como sendo o processo de formação do sem-terra brasileiro, na constituição específica do sujeito Sem Terra: de trabalhador sem (a) terra a membro de uma organização social de luta pela Reforma Agrária, a lutador do povo, no sentido de que preocupado com questões que dizem respeito ao futuro do país, e ao destino histórico do povo brasileiro. E ainda que seja necessário buscar a gênese desta formação em um contexto histórico que antecede e extrapola o MST, não é mais possível hoje entender quem são os sem-terra no Brasil fora da história do MST. A atuação do Movimento na formação dos Sem Terra ajudou a constituir a própria expressão sem-terra, há bem pouco tempo incluída nos dicionários da língua portuguesa.

Afirmo, então, que este processo também pode ser interpretado como um processo de formação humana, e mesmo como a materialização de um determinado modo de produção da formação humana, cuja matriz é o próprio Movimento como sujeito e princípio educativo. Isto porque, se fazemos o esforço de buscar compreender o sentido mais profundo da experiência humana de ser Sem Terra, ou ser do MST, nos encontramos com um movimento pedagógico de formação de sujeitos sociais e de seres humanos, que nos remete às questões de origem da própria reflexão pedagógica, ou da reflexão da educação como formação humana: como nos humanizamos, ou nos formamos como humanos? Como se educa uma pessoa para que se desenvolva em sua condição humana? Quais os valores que movem nossa intencionalidade educativa? Para que postura diante da sociedade nossa prática tem educado? (7) 
Nesta perspectiva, podemos dizer que a herança que o MST deixará para seus descendentes será bem maior do que a quantidade de terra que conseguir libertar da tirania do latifúndio; será um jeito de ser humano e de tomar posição diante das questões de seu tempo; serão os valores que fortalecem e dão identidade aos lutadores do povo de todos os tempos, de todos os lugares. Talvez seja especialmente enquanto produto de uma obra educativa que os Sem Terra possam ser vistos pela história como mais um elo que se formou em uma longa tradição de lutadores sociais que fazem a história da humanidade. Enraizamento no passado, combinado com projeto de futuro.

\section{Os Sem Terra se educam no movimento da luta social e da organização coletiva de que são sujeitos, e que os produz como sujeitos}

Os Sem Terra se educam, quer dizer, se humanizam e se formam como sujeitos sociais no próprio movimento da luta que diretamente desencadeiam. Estão sendo chamados hoje de lutadores do povo e sua atuação acaba projetando uma identidade que é sua, mesmo que não esteja como consciência e como prática em cada um dos sem-terra do MST. Uma contradição às vezes politicamente complicada, porque retarda o avanço da luta maior, mas pedagógica e culturalmente muito fecunda e desafiadora, desde que assumida cotidianamente como objeto de um trabalho intencionalmente educativo, do MST e de cada um dos seus integrantes e apoiadores.

A conjuntura e a história vêm desafiando o MST a assumir determinado jeito de fazer a luta pela terra, e este jeito vai conformando seus sujeitos. A trajetória que vem fazendo de um trabalhador sem (a) terra um membro de uma organização social de massas que luta pela Reforma Agrária, e deste sem-terra do MST um Sem Terra que passa a fazer lutas por um novo projeto de desenvolvimento do país (como a luta contra as políticas de privatização do atual governo brasileiro, por exemplo), sem deixar de continuar a lutar pela terra, é um processo de escolhas condicionadas pelo momento histórico. Se o MST tivesse existido em outra época, talvez a identidade Sem Terra fosse diferente.

Do ponto de vista da nossa reflexão sobre educação, há nesta análise duas idéias-força imbricadas uma na outra, e é importante destacá-las aqui. A primeira delas, que existe uma pedagogia que se constitui no movimento de uma luta social; a segunda, que uma luta social é mais educativa, ou tem um peso formador maior, à medida que seus sujeitos conseguem entranbá-la no movimento da história.

Os Sem Terra se educam participando diretamente, e como sujeitos, das ações da luta pela terra e de outras lutas sociais que aos poucos foram integrando à agenda do MST. É esta participação que humaniza as pessoas: primeiro no sentido de que devolve à vida social pessoas que estavam dela excluídas (esta é 
pelo menos uma das interpretações que podem ser feitas da expressão paramos de morrer...); segundo, no sentido de que a pedagogia da luta educa para uma determinada postura diante da vida: nada é impossípel de mudar, e quanto mais inconformada com o atual estado de coisas mais humana é a pessoa; ou seja, exatamente o contrário da pedagogia da socialização que predomina nos chamados meios educacionais, onde estar em movimento e ter atos de contestação ou rebeldia é sempre visto como "má-educação": é preciso afastar-se daqueles baderneiros do MST!

Desde este outro ponto de vista, ao contrário, dizemos que participar do movimento da luta vai educando um jeito específico de ser humano, que potencializa o principal traço da humanidade: a possibilidade de fazer-se e refazer-se a si próprio, enquanto contesta a ordem estabelecida, problematiza e propõe valores, transforma a realidade e se produz como sujeito da história. As lutas sociais produzem as transformações históricas, e o fazem à medida que conseguem conformar os sujeitos sociais capazes de operá-las e, ainda mais, de consolidar os novos parâmetros de vida em sociedade que vão criando neste movimento.

É também a participação no movimento da luta que politiza os Sem Terra, no sentido de que passam a compreender o seu problema específico num contexto mais amplo, e como parte de uma correlação de forças sociais e políticas que não se alteram apenas porque decidiram agir para transformar sua situação particular. Muitos sem-terra quando decidem participar de uma ocupação ou entrar num acampamento, o fazem movidos pela necessidade, mas também por uma visão ainda ingênua de mundo: consideram que se são trabalhadores do campo e se dispõem a trabalhar na terra, é justo que logo a consigam e então todos os seus problemas estarão resolvidos. Pouco adianta as lideranças fazerem longos discursos para explicar que a realidade é diferente; somente experimentando pessoalmente os embates da luta pela terra é que, aos poucos, aprenderão de que relações sociais fazem parte, e o que contestam mais profundamente em cada um dos atos coletivos de que participam.

Este é um dos momentos importantes de um processo de formação que começa a relacionar o movimento da luta, no seu imediato e em sua conjuntura, e o movimento da história, geralmente mais lento e complexo.

Um dos processos educativos fundamentais da participação dos sem-terra na luta está em seu enraizamento numa coletividade em movimento, que embora seja sua própria construção (os Sem Terra são o MST), acaba se constituindo como uma referência de sentido que está além de cada Sem Terra, ou mesmo além do seu conjunto, e que passa a ter um peso formador, ao meu ver decisivo, no processo de educação dos Sem Terra. É a intencionalidade política e pedagógica do MST que garante o vínculo da luta imediata com o movimento da história.

A trajetória do MST foi sendo desenhada pelos desafios de cada momento histórico. À medida que os sem-terra se enraízam na organização coletiva que os 
produz como sujeitos, passam a viver experiências de formação humana encarnadas nesta trajetória. Mesmo que cada pessoa não tenha consciência disso, toda vez que toma parte das ações do Movimento, fazendo uma tarefa específica, pequena ou grande, ela está ajudando a construir esta trajetória e a identidade Sem Terra que lhe corresponde; e está se transformando e se reeducando como ser humano.

Tornar consciente e reflexivo este processo é um dos grandes desafios pedagógicos do MST, e uma das razões de valorizar cada vez mais as atividades específicas de educação. Sem isto, os novos sujeitos sociais não conseguirão se tornar sujeitos políticos, capazes de efetivamente fazer diferença no desenrolar da luta de classes, e na reconstrução de nosso projeto de humanidade. Não há como ser um sujeito político sem saber-se um sujeito social, e não há como saber-se um sujeito social, coletivo, sem compreender-se no processo histórico da luta e da formação de seus sujeitos.

\section{A luta social que forma sujeitos sociais, políticos, humanos, é a que produz e reproduz um movimento sócio-cultural maior do que ela mesma}

Esta idéia desdobra um dos aspectos da anterior: uma luta social tem um peso formador maior quando entranhada no movimento da história. E o movimento da história nos remete a processos de transformação social mais lentos e profundos, que se reproduzem também no plano da cultura, entendida aqui no sentido de modo de vida que caracteriza determinado grupo, lugar e/ou momento da história.

Afirmar que uma luta social produz e reproduz um movimento sóciocultural, maior do que ela mesma, significa dizer que sua dinâmica encarna, exige e projeta dimensões relacionadas ao modo de vida das pessoas em uma sociedade: mexe com valores, posturas, visão de mundo, tradições, costumes..., enfim, provoca a reflexão da sociedade sobre si mesma. Por isto as ações de seus sujeitos acabam tendo um sentido histórico e uma influência política que extrapola o seu conteúdo específico, os interesses sociais imediatos e a consciência política que produziu não somente as ações, mas seus próprios sujeitos.

É algo assim que está sendo percebido na luta pela Reforma Agrária conduzida pelo MST. O Movimento dos Sem Terra passou a ser referência de contestação social, ou mesmo de combate ao modelo capitalista em sua versão neoliberal, em um processo ainda não de todo refletido e compreendido pelos Sem Terra, e mesmo pelo conjunto da sociedade. Isto está acontecendo não apenas porque a luta pela terra é uma luta justa. Sua referência vem sendo construída porque esta luta social e humanamente justa está sendo feita de um modo que é capaz de colocar em cena novos, e para alguns inusitados, sujeitos, ao mesmo tempo que os apresenta encarnando valores humanos e ideais libertários 
quase tão antigos quanto a humanidade. Desgarrados da terra, pobres de tudo que de repente, ou nem tanto, agarram em suas mãos a luta pela própria "salvação social e humana", e se mostram à sociedade como cidadãos, lutadores do povo, seres humanos com dignidade.

Este jeito de fazer a luta social que produz sujeitos sociais é exatamente o jeito de vincular a luta específica com as grandes questões humanas e sociais de seu tempo. A natureza da luta pela terra, que mistura a luta pelo direito ao trabalho diretamente com a vida que a própria terra simboliza, parece predispor para esta sensibilidade. Mas nem todas as lutas pela terra que aconteceram na história foram capazes de produzir sujeitos sociais, identidades políticas e culturais que fossem elos de um processo histórico mais amplo.

Os Sem Terra se fortalecem como sujeitos e se firmam como identidade, à medida que suas ações conseguem pôr em questão e, ao mesmo tempo, afirmar valores, provocando as pessoas a pensar para além da ação que enxergam. Cada vez que caem cercas a sociedade é obrigada a olhar-se e a discutir o tamanho das desigualdades, o tamanho da opulência e da miséria, o tamanho da fartura e da fome... (Pedro Tierra, poeta, 1995). Em uma ocupação de latifúndio há um valor posto em questão: o da propriedade em si mesma; e há valores afirmados ou reafirmados: o da vida e do direito de lutar por ela.

Quando, nos assentamentos, os Sem Terra buscam construir novas relações sociais de trabalho, e novos formatos para a vida em comunidades do campo, afirmam uma cultura centrada no bem-estar da coletividade, e se contrapõem, portanto, à absolutização do indivíduo, que é característica dominante da sociedade capitalista. Quem visita um assentamento, ou mesmo um acampamento de Sem Terra, sai com a impressão, e talvez a reflexão, de que há outras possibilidades de como viver, e que há questões, saberes, afetos e relações de outra ordem, acontecendo não muito longe de um tipo de vida que consideravam como o único possível.

Em todos estes processos temos a afirmação de novos seres humanos, ou de um novo jeito de ser humano. Neste sentido voltamos à reflexão constituinte deste raciocínio todo: é exatamente prestando atenção nas pessoas, e em como a dinâmica do Movimento é capaz de produzir gente, seres humanos que se convertem em sujeitos sociais, que é possível perceber na atuação do MST certos pressentimentos de futuro, por sua vez encarnados em preciosos tesouros do passado, no sentido de que sua identidade se entranha em um movimento sócio-cultural que projeta uma concepção de relações sociais e uma forma de ser humano que não correspondem àqueles produzidos hegemonicamente pela sociedade capitalista atual.

Por contradição, embora isto represente um broto politicamente tão frágil, acaba encontrando receptividade na própria sociedade cujas forças políticas 
hegemônicas o combatem, exatamente pelo caos social e a desesperança humana produzida pela lógica desta sociedade e desta hegemonia. Cada vez mais cresce o número de pessoas ávidas de esperanças e de propostas, e é isto que julgam enxergar em movimentos como o MST, e em figuras humanas como a dos Sem Terra.

Embora não tenha planejado isto, o MST acaba tendo de assumir desafios próprios do que não chega a realizar por si mesmo, mas que acaba projetando através de suas ações. Em outras palavras, o MST tem sido chamado ao compromisso de ser fiel ao movimento da história que o fez nascer e crescer num tempo de crise social e de degradação humana. Este é um tempo que coloca na agenda mundial a possibilidade de transformações profundas no modelo de sociedade, no projeto de humanidade. Se vivemos neste tempo, nossas ações passam a ter um peso maior, porque se juntam à força de outras ações que definirão os rumos destas mudanças.

Pela pressão da conjuntura, e pelas escolhas que vem fazendo em sua trajetória, o MST projetou uma identidade coletiva que está tomando posição neste processo. Se dará conta deste desafio, e se historicamente fará diferença no desenlace deste movimento maior, é algo que somente o tempo poderá responder. Mas que deste processo já é possível extrair lições importantes, tanto do ponto de vista político quanto pedagógico, isto é algo que já podemos afirmar agora.

\section{No movimento da luta social que forma sujeitos há matrizes pedagógicas importantes a considerar em um projeto de educação vinculado a processos de transformação}

Podemos compreender o processo histórico de formação dos sem-terra do MST como constituidor de uma determinada matriz pedagógica, ou a materialização de um modo de produção da formação humana que tem o movimento como princípio educativo, a luta social como base conformadora deste movimento educativo, e a pedagogia da história como cimento principal que vai interligando as diversas dimensões deste movimento.

Afirmar o movimento como princípio educativo da formação dos Sem Terra é considerar que seu processo educativo básico está no movimento mesmo, no transformar-se transformando a terra, as pessoas, a história, a própria pedagogia, sendo esta a raiz e o formato fundamental da identidade pedagógica do próprio MST. Não é por acaso que especialmente nos acampamentos seja comum a expressão ser do Movimento é estar em movimento!

No Movimento os sem-terra aprendem que o mundo e o ser humano estão para ser feitos, e que o movimento da realidade, constituído basicamente de relações que precisam ser compreendidas, produzidas ou transformadas, deve ser o grande mestre deste fazer. 
De certo modo reproduzem em outra dimensão, e também politizam, o aprendizado básico que já têm como trabalhadores da terra, lavradores. $\mathrm{O}$ trabalho na terra, que acompanha o dia a dia do processo que faz de uma semente uma planta e da planta um alimento, ensina de um jeito muito próprio (que é também cultural, simbólico) que as coisas não nascem prontas, mas que precisam ser cultivadas; são as mãos do lavrador, da lavradora, as que podem trabalhar a terra para que chegue a produzir o pão. Este também é um jeito de compreender que o mundo está para ser feito e que a realidade pode ser transformada, desde que se esteja aberto para que ela mesma diga a seus sujeitos como fazer isto, assim como a terra vai mostrando ao lavrador como precisa ser trabalhada para ser produtiva. Deste trabalho vem o aprendizado da paciência: não adianta apressar o tempo; da persistência: é preciso trabalhar todos os dias; e também da resistência diante dos percalços do cultivo: é preciso aprender a recomeçar tudo de novo e não abandonar a terra, quando intempéries cortam um processo de cultivo. Não é difícil enxergar, no jeito dos sem-terra conduzirem a sua luta, os traços que trazem de volta alguns destes saberes da sua relação com a terra.

Neste processo o MST se constitui como principal sujeito do movimento pedagógico da formação dos Sem Terra. Os sem-terra se educam como Sem Terra (sujeito social, pessoa humana, nome próprio) sendo do MST, o que quer dizer, construindo o Movimento que produz e reproduz sua própria identidade ou conformação humana e histórica. É sujeito pedagógico porque há uma intencionalidade ou um projeto educativo em suas ações, ainda que não totalmente refletida e consciente.

Esta intencionalidade não está primeiro no campo da educação, mas no próprio caráter do MST, produzido em sua trajetória histórica de participação na luta de classes em nosso país, no recorte específico de sua questão agrária. É através de seus objetivos, princípios, valores e jeito de ser, que o Movimento intencionaliza suas práticas educativas, ao mesmo tempo que, aos poucos, também começa a refletir sobre elas, à medida que se dá conta de sua tarefa histórica: além de produzir alimentos em terras antes aprisionadas pelo latifúndio, também deve ajudar a produzir seres humanos capazes de assumir o comando de seu próprio destino social, histórico.

Enquanto sujeito pedagógico o MST não cria uma nova pedagogia, mas inventa um novo jeito de lidar com as pedagogias já construídas na história da formação humana. Em outras palavras, a Pedagogia do Movimento põe em movimento a própria pedagogia, mobilizando e incorporando em sua dinâmica diversas e combinadas matrizes pedagógicas. Tal como na lavração que seus sujeitos fazem da terra, o MST ao fazer a formação humana revolve, mistura e transforma diferentes componentes educativos, produzindo uma síntese pedagógica que não é original, mas também não é igual a qualquer pedagogia já proposta, se tomada em si mesma, exatamente porque a sua referência de sentido está no Movimento. 
Em outras palavras, o MST em sua dinâmica tem ajudado a produzir uma matriz pedagógica que é síntese e combinação de diversas matrizes pedagógicas ao mesmo tempo, e nisto talvez esteja uma das principais lições de pedagogia que se pode extrair de sua dinâmica, para pensar as práticas de educação como um todo. Não se trata de centrar um projeto educativo, ou educacional, em uma única pedagogia, ou eleger uma determinada prática social como sendo $a$ prática educativa por excelência; menos ainda de ir alterando esta escolha ao sabor de modismos teóricos da conjuntura. Não é assim que os seres humanos se educam. Não há uma prática capaz de concentrar em si mesma, e de uma vez para sempre, todas as virtualidades pedagógicas necessárias à formação humana.

É o movimento das práticas, diversas, por vezes mesmo contraditórias entre si, o que educa sujeitos, humaniza. Ativar este movimento, desencadear processos que combinem diferentes práticas pedagógicas, e refletir para que constituam um movimento educativo coerente, no sentido de que desenvolvido em torno de valores e de princípios comuns, eis a grande tarefa dos educadores e das educadoras. Tanto mais daqueles comprometidos com a formação dos sujeitos das transformações sociais, e do combate pela dignidade humana, para todos. Exatamente porque em nosso tempo, como em outros, o princípio da inércia pedagógica geralmente se realiza nas práticas sociais como politicamente conservador e, até mesmo, reacionário.

$\mathrm{Na}$ experiência pedagógica do MST, a luta social aparece como base da educação dos Sem Terra, exatamente porque aciona o movimento como princípio educativo, e se mistura com outros processos básicos ou potencialmente (con)formadores do ser humano: a relação com a terra, o trabalho, a construção de novas relações sociais de produção no campo, a vida cotidiana em uma coletividade, a cultura, a história, o estudo... A luta mesma, afinal, transfigura-se ou desdobra-se em cada uma destas dimensões que se produziram como pedagogias ao longo da história da humanidade. Por isto afirmei que é o próprio movimento da luta o grande educador dos Sem Terra.

Isto nos faz, afinal, pensar em questões e reflexões de outra ordem para compreender e fazer educação desde preocupações humanizadoras, e desde processos coletivos de transformação social.

Algumas das questões fundamentais de que, nós, educadores, deveríamos nos ocupar, na perspectiva do raciocínio aqui apresentado, são as seguintes: que práticas sociais estão ajudando a formar os sujeitos com quem trabalhamos? Que pedagogia cada uma delas encarna? Como podemos organizá-las, refleti-las, colocá-las em um mesmo movimento pedagógico, de modo que constituam um projeto de educação vinculado ao movimento da história? Como construir tempos e espaços educativos que se mantenham em movimento? O que significa em nossa formação como educadores, educadoras, assumir o movimento (também das pedagogias) como princípio educativo? 


\section{É possível pensar na escola como um lugar de formação humana que tenha o movimento como princípio educativo}

A pedagogia do movimento e o movimento das pedagogias que formam os Sem Terra não cabem na escola, mas historicamente o MST vem demonstrando que a escola cabe e tem um lugar cada vez mais importante em sua intencionalidade pedagógica.

Do processo histórico da formação dos Sem Terra podemos extrair algumas matrizes pedagógicas básicas para construir uma escola preocupada com a formação humana e com o movimento da história. Mas deve-se ter presente que a pedagogia que forma novos sujeitos sociais, e que educa seres humanos não cabe numa escola. Ela é muito maior e envolve a vida como um todo. Certos processos educativos que sustentam a identidade Sem Terra jamais poderão ser realizados dentro de uma escola. Mas o MST também vem demonstrando, em sua trajetória, que a escola pode fazer parte de seu movimento pedagógico, e que precisa dela para dar conta de seus desafios como sujeito educativo.

No MST a luta por escola começou junto com a luta pela terra. Mas é preciso compreender que a preocupação consciente dos Sem Terra com educação, e especialmente com o tipo de educação das novas gerações, para que continuem sua luta, seu projeto, somente pode surgir quando se dão conta de que estão construindo uma organização duradoura e uma luta de vida inteira. Antes disso até lutam pela escola de seus filhos, mas de modo geral sem perceber que isto tem relação com suas outras lutas, e com o desenlace da história que puseram em movimento.

A luta dos Sem Terra pela escola foi iniciada porque o MST deu um formato à luta pela terra que a produziu como necessidade: luta das famílias, luta que incluiu também a dimensão dos assentamentos (enquanto novas comunidades do campo) em seu cotidiano. Por sua vez, o movimento histórico desta luta foi aos poucos redimensionando o lugar da escola em sua dinâmica: primeiro ela foi construída como um direito, e aos poucos ela vai sendo construída como um lugar onde também pode acontecer a formação do sujeito Sem Terra. A escola pública continua a ser vista como um direito, mas, hoje, Sem Terra que honre este nome é o que se sabe com direito e dever de estudar, exatamente porque sem compreender a realidade não é possível transformá-la, e tanto mais quando ela se apresenta de forma tão complexa como agora.

O esforço feito pelo MST de incluir a escola em sua dinâmica vem trazendo historicamente algumas implicações importantes: do primeiro movimento, o reforço à luta da classe trabalhadora pela escola pública, e a produção da cultura do direito à escola no campo e do campo. Do segundo movimento, a proposição 
de uma escola que construa sua pedagogia vinculada a um movimento pedagógico mais amplo, reconhecendo-se como lugar de formação humana, e de uma formação humana ética e politicamente comprometida com a produção dos sujeitos capazes de fazer as transformações sociais, que cada vez mais aparecem como necessárias para a própria restituição da dignidade humana.

A escola que cabe na pedagogia do movimento é, pois, uma escola que não cabe nela mesma. Não é a escola de um modelo pedagógico fechado (por mais "revolucionário" que se pretenda), de um método de ensino, de uma estrutura; é bem mais um jeito de ser escola, uma postura diante da tarefa de educar, um processo ou um movimento pedagógico, um ambiente educativo que justamente seja capaz de produzir e reproduzir o Movimento como princípio educativo.

A escola projetada pela pedagogia do movimento é, pois, uma escola em movimento: movimento de pedagogias, movimento de sujeitos humanos. E este movimento acontece em torno de duas referências básicas: ser um lugar de formação humana, no sentido mais universal desta tarefa; e olhar para o Movimento como sujeito educativo que precisa da escola para ajudar no cultivo da identidade Sem Terra, e na continuidade de seu projeto histórico. Quando é assim, cada uma das pequenas coisas que acontecem no dia a dia da escola passa a ter um outro sentido, não porque sejam coisas que nela nunca antes aconteciam (em alguns casos também isto), mas porque olhadas e feitas desde uma outra intencionalidade.

Na combinação destas duas referências, que sintetizam a idéia de uma escola que tem o Movimento como princípio educativo, um dos processos pedagógicos básicos está no enraizamento projetivo, raiz e projeto combinados como estratégia de formação dos sujeitos sociais, e dos seres humanos que os encarnam.

A educação dos sem-terra do MST começa com o seu enraizamento em uma coletividade, que não nega o seu passado mas projeta um futuro que eles mesmos poderão ajudar a construir. Saber que não está mais solta no mundo é a primeira condição de a pessoa se abrir para esta nova experiência de vida. Este costuma ser o sentimento que diminui o medo em uma ocupação, ou que faz enfrentar a fome em um acampamento.

O enraizamento, nos ensina Simone Weil (8), é uma das necessidades do ser humano. E ter raiz, nos diz ela, é participar real e ativamente de uma coletividade que conserva vivos certos tesouros do passado e certos pressentimentos do futuro. Enraizado é o sujeito que tem laços que permitem olhar tanto para trás como para frente. Ter projeto, por sua vez é ir transformando estes pressentimentos de futuro em um horizonte pelo qual se trabalha, se luta. Não há, pois, como ter projeto sem ter raízes, porque são as raízes que nos permitem enxergar o horizonte.

O enraizamento projetivo é, pois, um dos processos fundamentais de formação dos lutadores do povo, assim como talvez o seja de qualquer ser humano. 
A escola não é capaz de enraizar as pessoas porque não tem em si mesma a materialidade pedagógica necessária para tanto. Mas a escola, dependendo das opções pedagógicas que faça, pode ajudar a enraizar ou a desenraizar; pode ajudar a cultivar utopias ou um presenteísmo mórbido. Toda vez que uma escola desconhece e/ou desrespeita a história de seus alunos, toda vez que se desvincula da realidade dos que deveriam ser seus sujeitos, não os reconhecendo como tal, ela escolhe ajudar a desenraizar e a fixar seus educandos num presente sem laços. E se isto acontecer com um grupo social desenraizado ou com raízes muito frágeis, isto quer dizer que estas pessoas estarão perdendo mais uma de suas chances (e quem garante que não a última?) de serem despertadas para a própria necessidade de voltar a ter raiz, a ter projeto. Do ponto de vista do ser humano isto é muito grave, é violentamente desumanizador.

A escola cultiva e fortalece os processos de enraizamento humano quando trabalha com a memória coletiva, recuperando e trabalhando com os tesouros do passado, aprendendo e ensinando com a pedagogia da história; também quando incorpora em seu movimento pedagógico a mistica, que é o sentimento materializado em símbolos que ajudam as pessoas a manter a utopia coletiva. No MST a mística é uma das dimensões básicas do processo de formação dos Sem Terra, e a escola pode ajudar a cultivar este elo simbólico entre a memória e a utopia, entre a raiz e o projeto. Fazendo isto certamente estará trabalhando com valores, que são os que sustentam qualquer processo de formação humana. Raiz e projeto se constituem de valores; e são os valores que movem uma coletividade; a escola pode criar um ambiente educativo que recupere, forme, fortaleça os valores verdadeiramente humanos, e então estará efetivamente contribuindo para que o movimento educativo se produza e reproduza também dentro dela.

Que seja assim, ou de outro jeito, depende muito da postura dos educadores, dispostos ou não a reconhecer o Movimento como um sujeito educador, e a se deixar educar pelo movimento e pela pedagogia da história. Em alguns lugares isto significa virar a escola de ponta-cabeça, e virar muitas de suas concepções de educação também de ponta-cabeça (9). Mas não é disso, afinal, que está precisando a escola, e que estamos precisando todos nós, para resgatar nossa própria humanidade, e o sentido de continuarmos na tarefa de educar?

Notas

1 Para um maior aprofundamento sobre a história do MST, ver capítulo 2 de Roseli Salete Caldart, Escola é mais do que escola na Pedagogia do Movimento Sem Terra; João Pedro Stedile \& Bernardo Mançano Fernandes, Brava gente. A trajetória do MST e a luta pela terra no Brasil, São Paulo, Fundação Perseu Abramo, ambos de 1999.

2 Ciranda Infantil é o nome dado pelo MST a tempos e espaços educativos dos Sem Terrinha da faixa etária dos zero aos seis anos. 
3 Sem Terra, com letras maiúsculas e sem hífen, é o nome próprio que identifica os semterra do MST. A expressão "sem-terra" indica a categoria social de trabalhadores e trabalhadoras do campo que não têm terra e que passam a requerê-la como direito. Trata-se de um vocábulo recente nos dicionários de língua portuguesa, uma das conquistas culturais da luta pela terra no Brasil. Mas em seu nome, os Sem Terra, mantêm a grafia original de seu nascimento como sujeitos que criaram o MST.

4 Sebastião Salgado, um fotógrafo brasileiro internacionalmente reconhecido pela sua arte e pela sua identificação com causas sociais relevantes, fez recentemente uma declaração que me parece importante registrar para complementar esta reflexão que não poderá ser feita mais profundamente aqui: "Para mim, o Movimento dos Sem Terra é um dos únicos movimentos - senão o único - que reúne em sua ação as lutas pela dignidade e pela cidadania no Brasil. Sua ação é toda centrada em uma só preocupação, um só eixo: promover a real e justa divisão de renda no país que tem o sistema de distribuição mais injusto do mundo. Acompanho sua luta com atenção, desde o início. Creio também que sua maior importância está no fato de incorporar e materializar todas as experiências anteriores, e que este sistema injusto que domina nosso país vem tentando, ao longo dos anos, apagar da nossa memória. Vejo no Movimento dos Sem Terra as experiências acumuladas pelas Ligas Camponesas, pelas federações de trabalhadores agrários, - as Fetags - pelas comunidades eclesiais de base. É um movimento ć́vico sério, que merece o respeito de todos os brasileiros e uma atenção real e corajosa por parte das autoridades. Qualquer brasileiro que tenha um mínimo de responsabilidade, que tenha consciência da situação social real de nosso país, tem o dever de acompanhar e apoiar o trabalho e a luta do MST. A história nos trouxe até um ponto em que foi preciso duvidar de todas as certezas. A esta altura, depois de ter passado por esse processo árduo, sinto-me no direito de expressar, com serenidade, que se poucas certezas sobrevivem em mim, uma delas é o valor e a dignidade do Movimento dos Sem Terra. Apoiar o MST é preservar o meu direito a continuar confiando na história, a despeito de tudo que o sistema vem fazendo no Brasil ao longo dos tempos." Este depoimento está na contracapa do livro, já referido, Brava gente. Sebastião Salgado organizou em 1997 a exposição Terra em homenagem à luta do MST.

5 Edward Thompson, A formação da classe operária inglesa. A árvore da liberdade, v. 1. Rio de Janeiro, Paz e Terra, 1987.

6 As próprias crianças têm expressado isto. Um exemplo é o texto final do Encontro Estadual dos Sem Terrinha do Rio Grande do Sul, realizado em outubro de 1999, feito através de uma Carta ao MST:

\section{"Querido MST:}

Somos filhos e filhas de uma história de lutas. Somos um pedaço da luta pela terra e do MST. Estamos escrevendo esta carta pra dizer a você que não queremos ser apenas filhos de assentados e acampados. Queremos ser SEM TERRINHA, pra levar adiante a luta do MST. No nosso país há muita injustiça social. Por isso queremos começar desde já a ajudar todo mundo a se organizar e lutar pelos seus direitos. Queremos que as crianças do campo e da cidade possam viver com dignidade. Não gostamos de ver tanta 
gente passando fome e sem trabalho pra se sustentar. Neste Encontro dos Sem Terrinha que estamos comemorando o Dia da Criança e os seus 15 anos, assumimos um compromisso muito sério: seguir o exemplo de lutadores como nossos pais e Che Guevara, replantando esta história por onde passarmos. Prometemos a você:

- Ser verdadeiros Sem Terrinha, honrando este nome e a terra que nossas famílias conquistaram.

- Ajudar os nossos companheiros que estão nos acampamentos, com doações de alimentos e roupas, incentivando para que continuem firmes na luta.

- Estudar, estudar, estudar muito para ajudar na construção de nossas escolas, nossos assentamentos, nosso Brasil.

- Ajudar nossas famílias a plantar, a colher, ter uma mesa farta de alimentos produzidos por nós mesmos e sem agrotóxicos.

- Embelezar nossos assentamentos e acampamentos, plantando árvores e flores, e mantendo tudo limpo.

- Continuar as mobilizações e fazer palestras nas comunidades e escolas de todo o Brasil.

- Divulgar o MST e sua história, usando nossos símbolos com grande orgulho.

Ainda não temos 15 anos, mas nos comprometemos a trabalhar para que você, nós, MST, tenha muitos 15 anos de lutas e de conquistas para o povo que acredita em você e é você. Um forte abraço de todos que participamos do $3^{\circ}$ ENCONTRO ESTADUAL DOS SEM TERRINHA DO RIO GRANDE DO SUL. Esteio, 12 de outubro de 1999.”

7 Uma reflexão sobre educação como formação humana, na perspectiva de nos reencontrarmos com as questões de origem da pedagogia, está em Miguel Arroyo, Trabalho-Educação e teoria pedagógica, em Gaudêncio Frigotto (org.), Educação e crise do trabalho: perspectivas de final de século, Petrópolis RJ, Vozes, 1998.

8 Em seu texto O desenraizamento (1943), que pode ser encontrado em Simone Weil, $A$ condição operária e outros estudos sobre a opressão (org. por Eclea Bosi), Rio de Janeiro, Paz e Terra, 1996.

9 Expressão inspirada na abordagem da história presente em Christopher Hill, O mundo de ponta-cabeça. Idéias radicais durante a Revolução Inglesa de 1640, São Paulo, Companhia das Letras, 1987.

Roseli Salete Caldart, doutora em Educação, é integrante do Coletivo Nacional do Setor de Educação do Movimento dos Trabalhadores Rurais Sem Terra (MST).

Texto produzido para o Primeiro Seminário Internacional do GT CLACSO Educação, Trabalho e Exclusão Social na América Latina, sessão sobre educação, trabalho e lutas sociais. Rio de Janeiro, dezembro 1999. As idéias básicas aqui desenvolvidas têm por base a tese de doutorado da autora, Escola é mais do que escola na Pedagogia do Movimento Sem Terra, Universidade Federal do Rio Grande do Sul, 1999 (Edição: Petrópolis, Vozes, janeiro de 2000). 